Supplement of The Cryosphere, 10, 2731-2744, 2016

http://www.the-cryosphere.net/10/2731/2016/

doi:10.5194/tc-10-2731-2016-supplement

(C) Author(s) 2016. CC Attribution 3.0 License.

(c) (i)

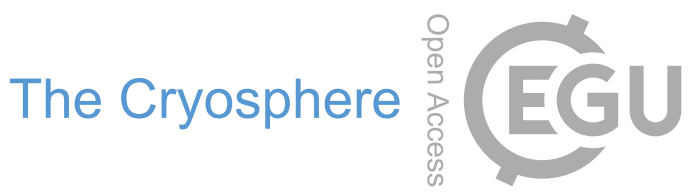

Supplement of

\title{
Simulating ice layer formation under the presence of preferential flow in layered snowpacks
}

Nander Wever et al.

Correspondence to: Nander Wever (wever@slf.ch)

The copyright of individual parts of the supplement might differ from the CC-BY 3.0 licence. 

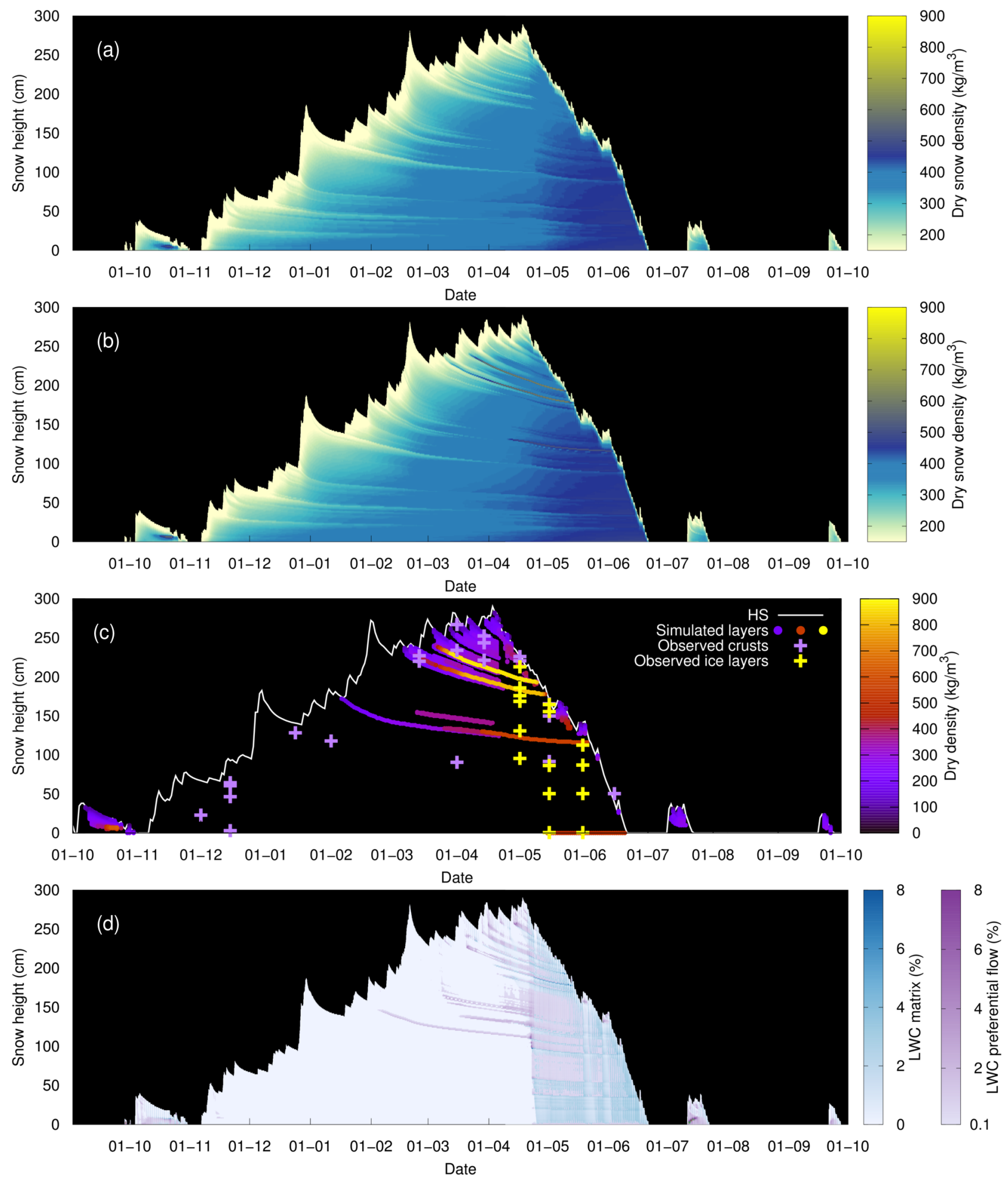

Figure S1: Dry snow density without considering preferential flow (a) and with preferential flow using high resolution simulations (b), validation with field observations (c) and liquid water content in the matrix and preferential flow domain for the simulation with preferential flow (d), for snow season 2000. In (c), modelled layers are shown when they are either a melt-freeze crust, or have a dry snow density exceeding $500 \mathrm{~kg} \mathrm{~m}^{-3}$. For visibility, values of LWC in preferential flow below $0.1 \%$ are ignored in (d). 

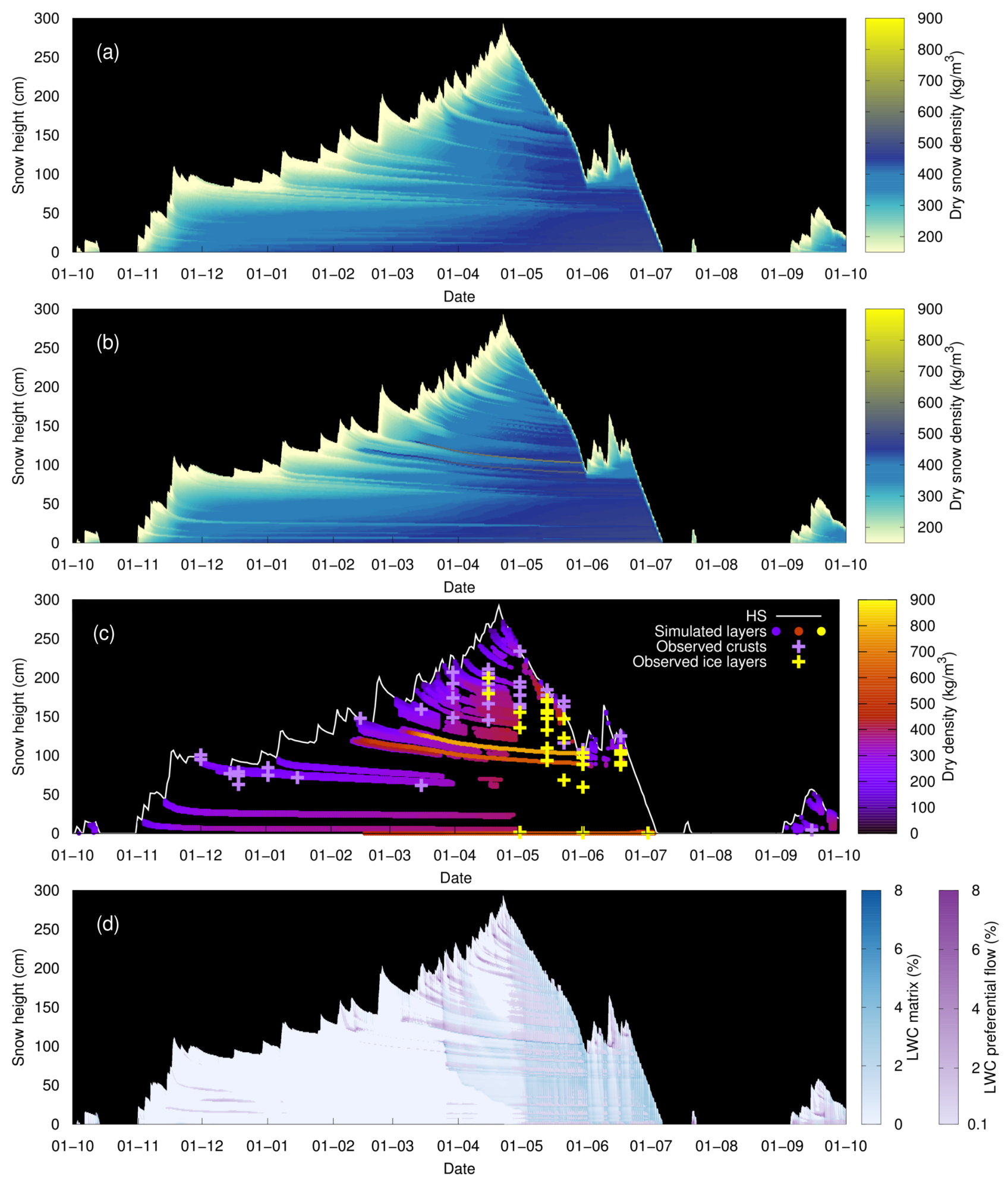

Figure S2: Dry snow density without considering preferential flow (a) and with preferential flow using high resolution simulations (b), validation with field observations (c) and liquid water content in the matrix and preferential flow domain for the simulation with preferential flow (d), for snow season 2001. In (c), modelled layers are shown when they are either a melt-freeze crust, or have a dry snow density exceeding $500 \mathrm{~kg} \mathrm{~m}^{-3}$. For visibility, values of LWC in preferential flow below $0.1 \%$ are ignored in (d). 

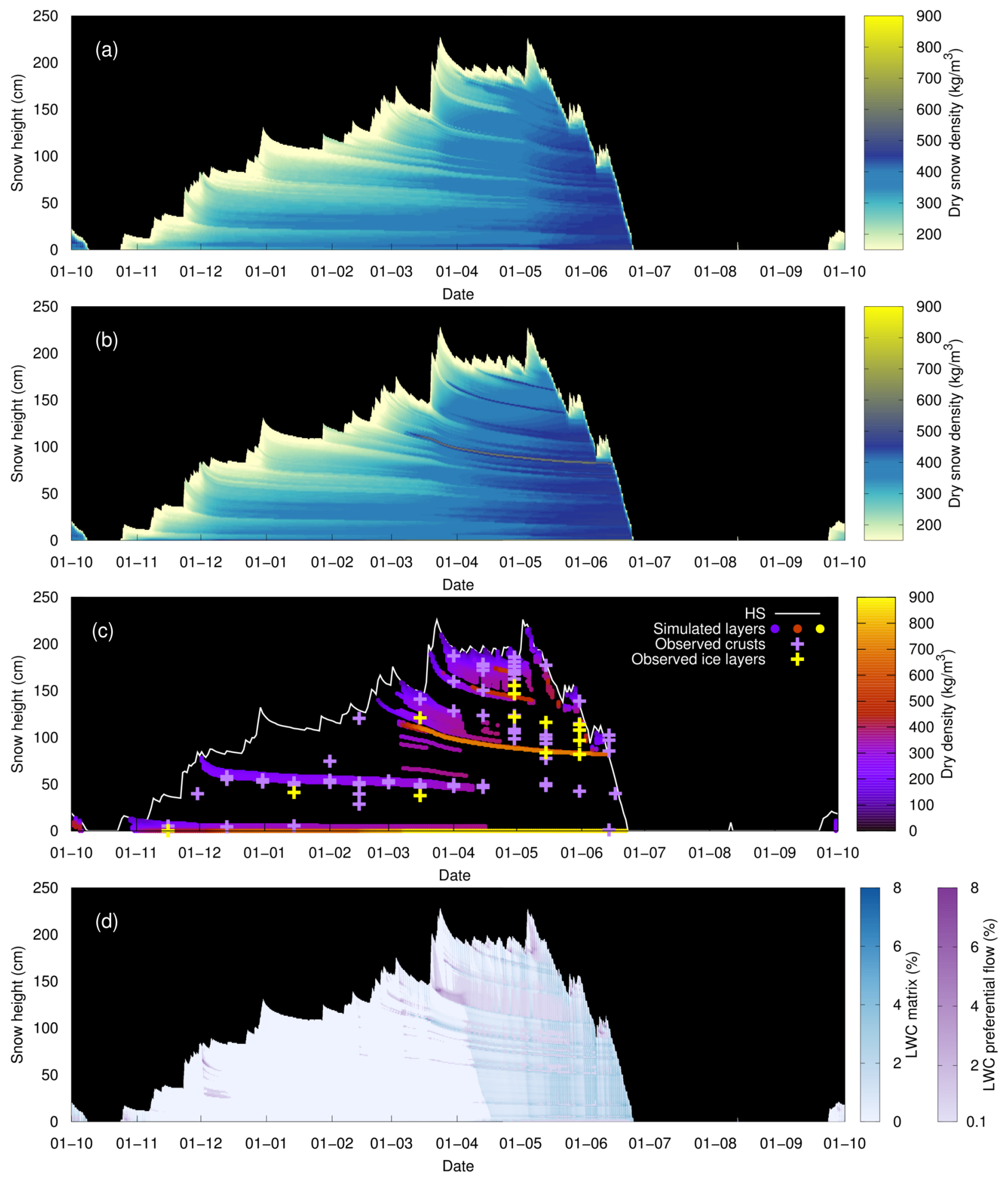

Figure S3: Dry snow density without considering preferential flow (a) and with preferential flow using high resolution simulations (b), validation with field observations (c) and liquid water content in the matrix and preferential flow domain for the simulation with preferential flow (d), for snow season 2002. In (c), modelled layers are shown when they are either a melt-freeze crust, or have a dry snow density exceeding $500 \mathrm{~kg} \mathrm{~m}^{-3}$. For visibility, values of LWC in preferential flow below $0.1 \%$ are ignored in $(\mathrm{d})$. 

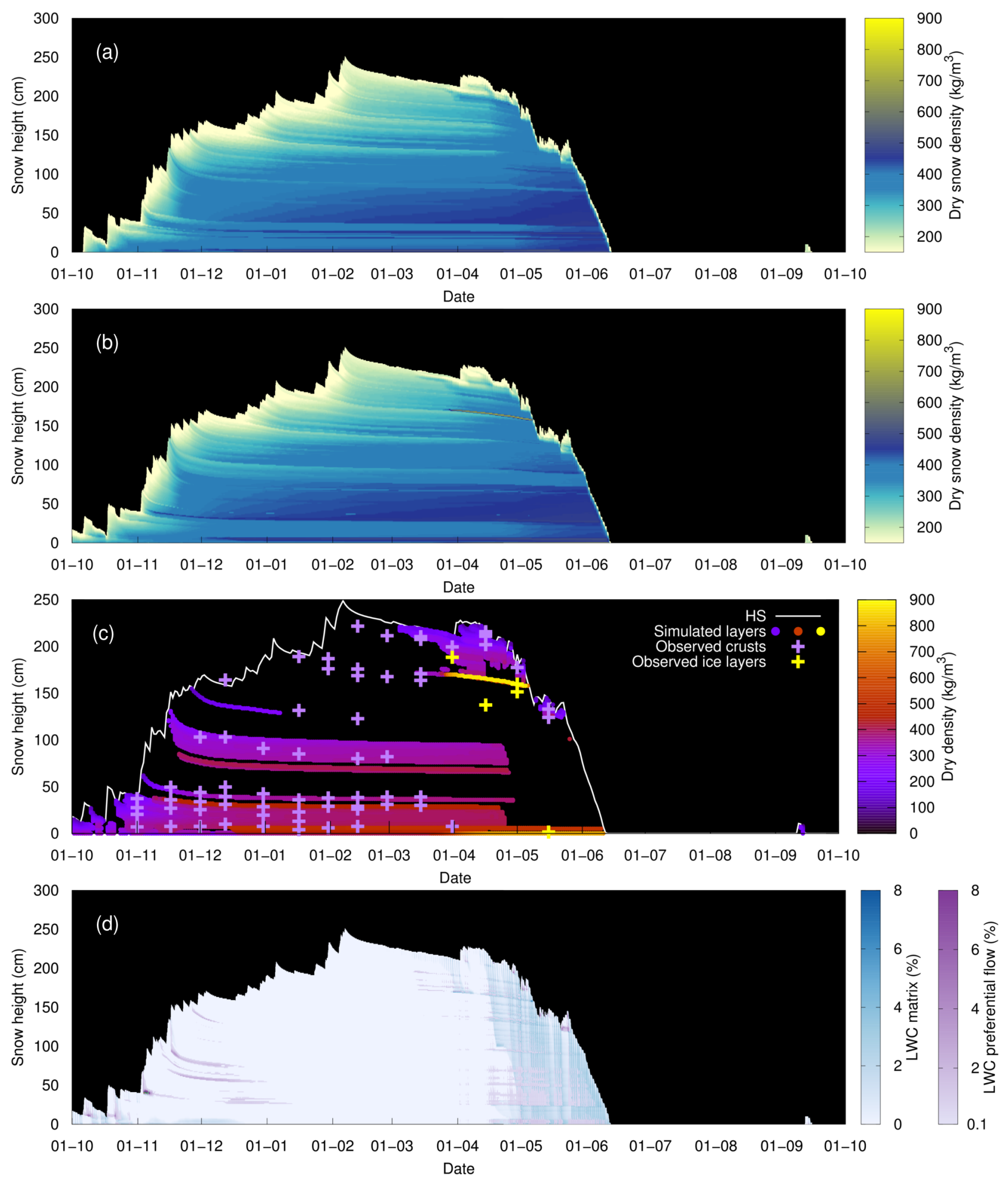

Figure S4: Dry snow density without considering preferential flow (a) and with preferential flow using high resolution simulations (b), validation with field observations (c) and liquid water content in the matrix and preferential flow domain for the simulation with preferential flow (d), for snow season 2003. In (c), modelled layers are shown when they are either a melt-freeze crust, or have a dry snow density exceeding $500 \mathrm{~kg} \mathrm{~m}^{-3}$. For visibility, values of LWC in preferential flow below $0.1 \%$ are ignored in $(\mathrm{d})$. 

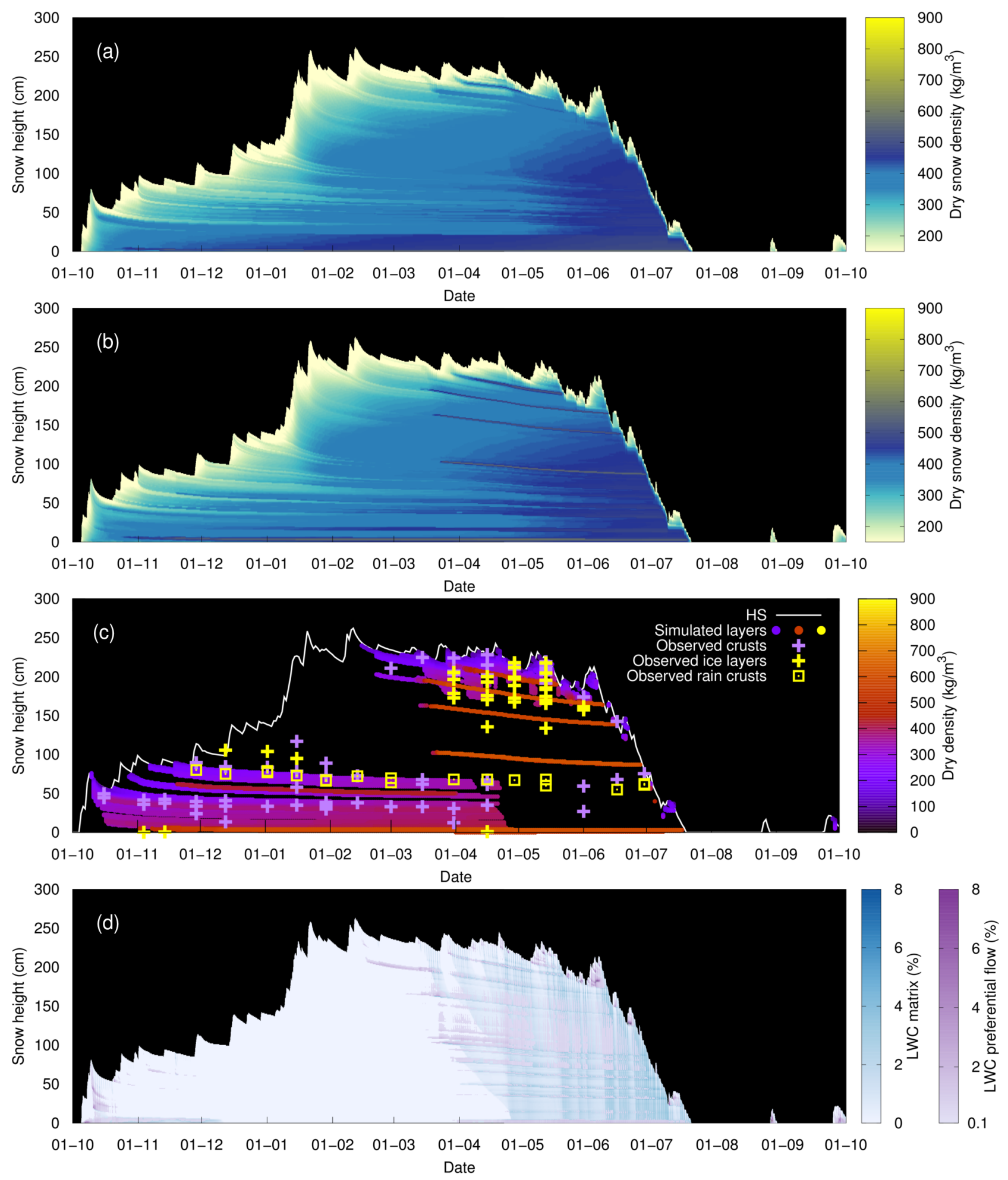

Figure S5: Dry snow density without considering preferential flow (a) and with preferential flow using high resolution simulations (b), validation with field observations (c) and liquid water content in the matrix and preferential flow domain for the simulation with preferential flow (d), for snow season 2004. In (c), modelled layers are shown when they are either a melt-freeze crust, or have a dry snow density exceeding $500 \mathrm{~kg} \mathrm{~m}^{-3}$. For visibility, values of LWC in preferential flow below $0.1 \%$ are ignored in (d). The observed ice layer due to rain is separately marked. 

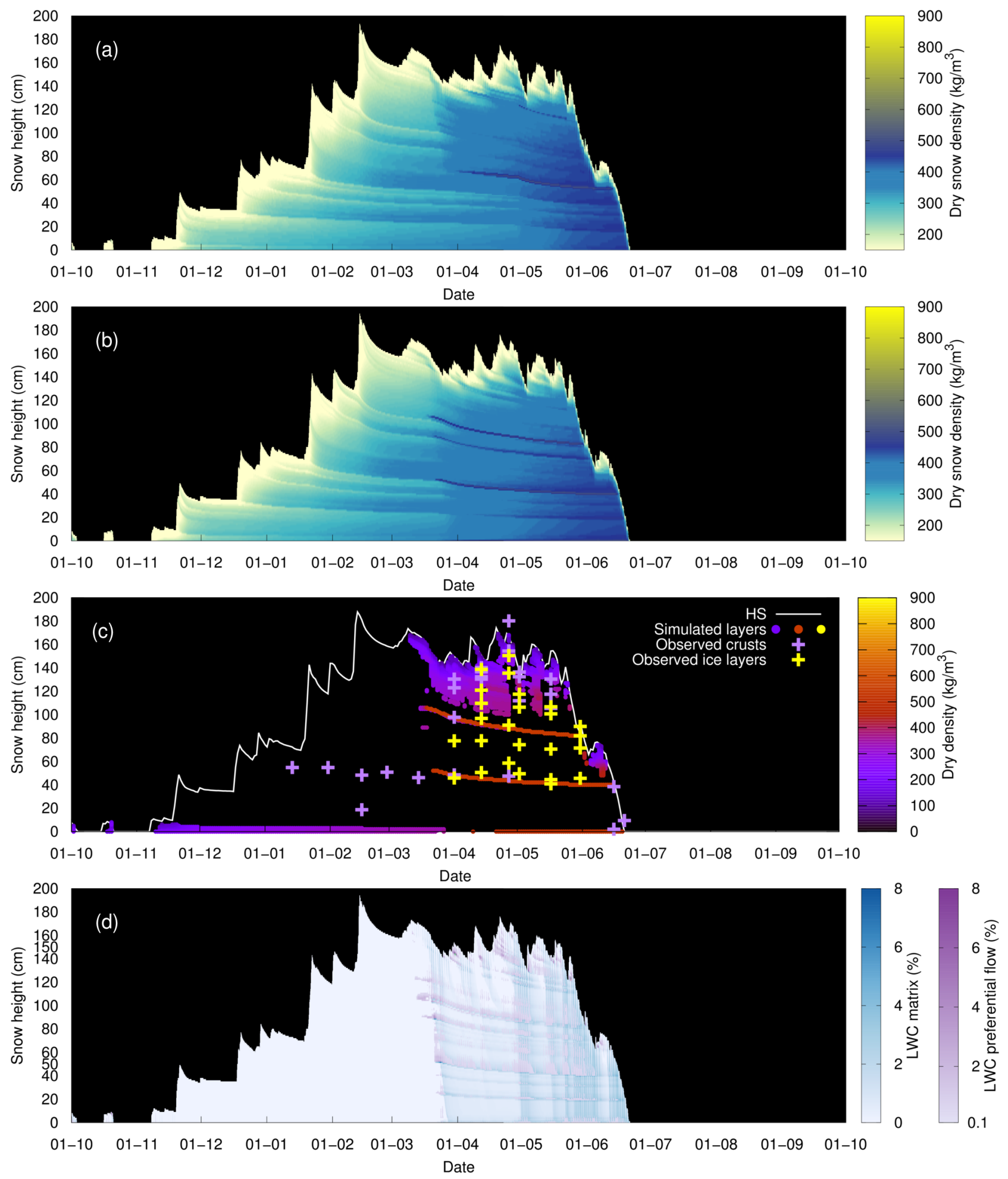

Figure S6: Dry snow density without considering preferential flow (a) and with preferential flow using high resolution simulations (b), validation with field observations (c) and liquid water content in the matrix and preferential flow domain for the simulation with preferential flow (d), for snow season 2005. In (c), modelled layers are shown when they are either a melt-freeze crust, or have a dry snow density exceeding $500 \mathrm{~kg} \mathrm{~m}^{-3}$. For visibility, values of LWC in preferential flow below $0.1 \%$ are ignored in (d). 

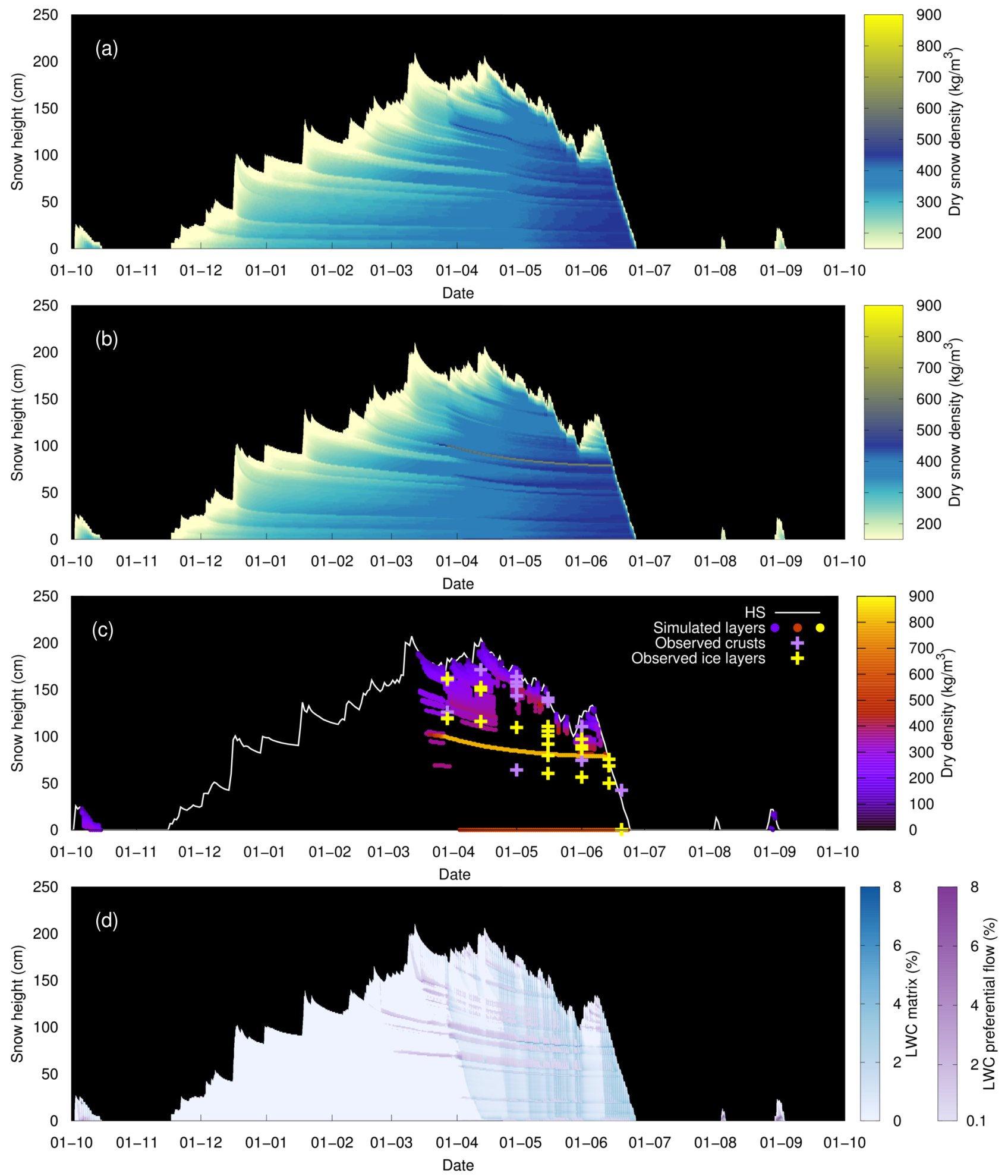

Figure S7: Dry snow density without considering preferential flow (a) and with preferential flow using high resolution simulations (b), validation with field observations (c) and liquid water content in the matrix and preferential flow domain for the simulation with preferential flow (d), for snow season 2006. In (c), modelled layers are shown when they are either a melt-freeze crust, or have a dry snow density exceeding $500 \mathrm{~kg} \mathrm{~m}^{-3}$. For visibility, values of LWC in preferential flow below $0.1 \%$ are ignored in (d). 

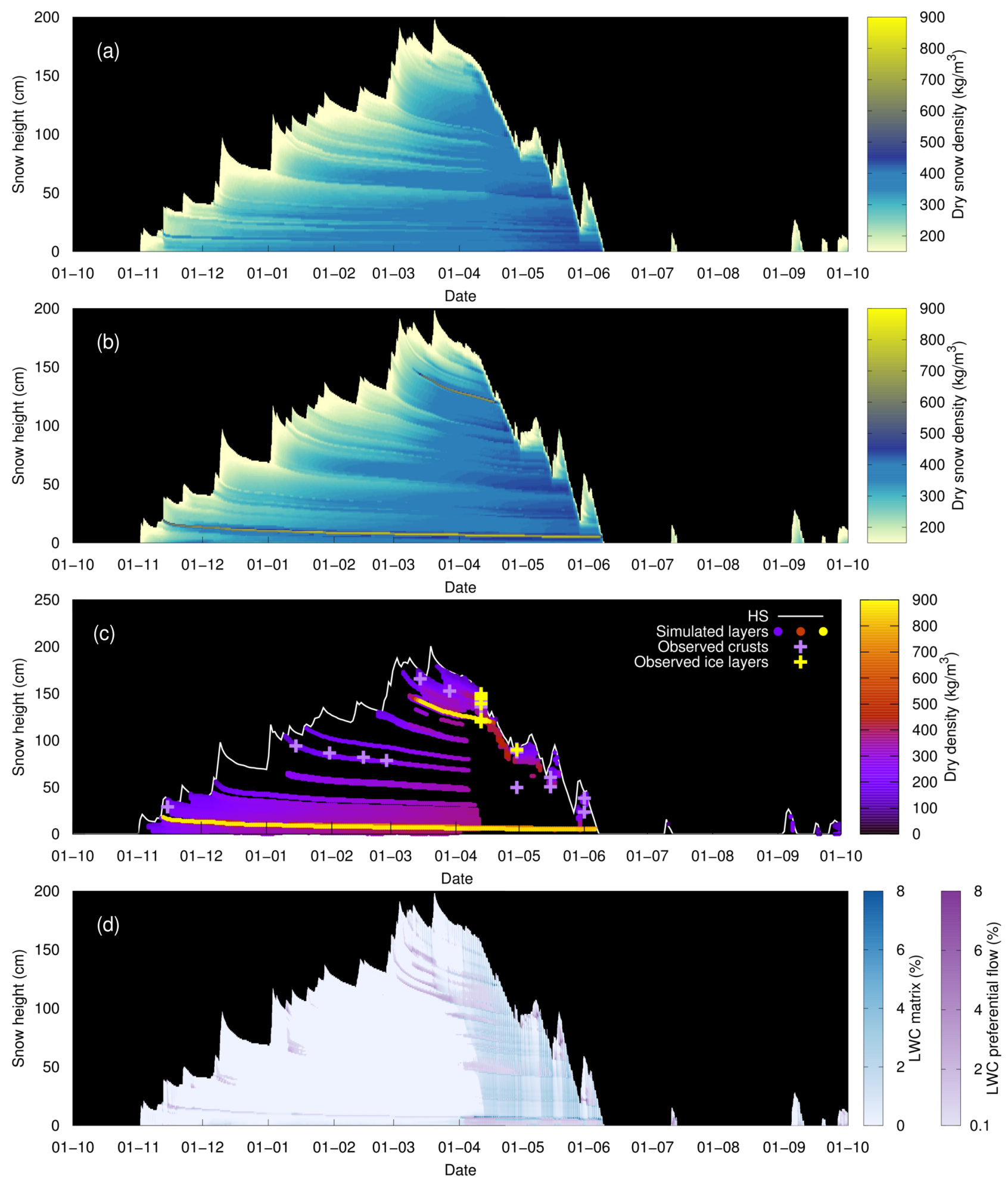

Figure S8: Dry snow density without considering preferential flow (a) and with preferential flow using high resolution simulations (b), validation with field observations (c) and liquid water content in the matrix and preferential flow domain for the simulation with preferential flow (d), for snow season 2007. In (c), modelled layers are shown when they are either a melt-freeze crust, or have a dry snow density exceeding $500 \mathrm{~kg} \mathrm{~m}^{-3}$. For visibility, values of LWC in preferential flow below $0.1 \%$ are ignored in (d). 

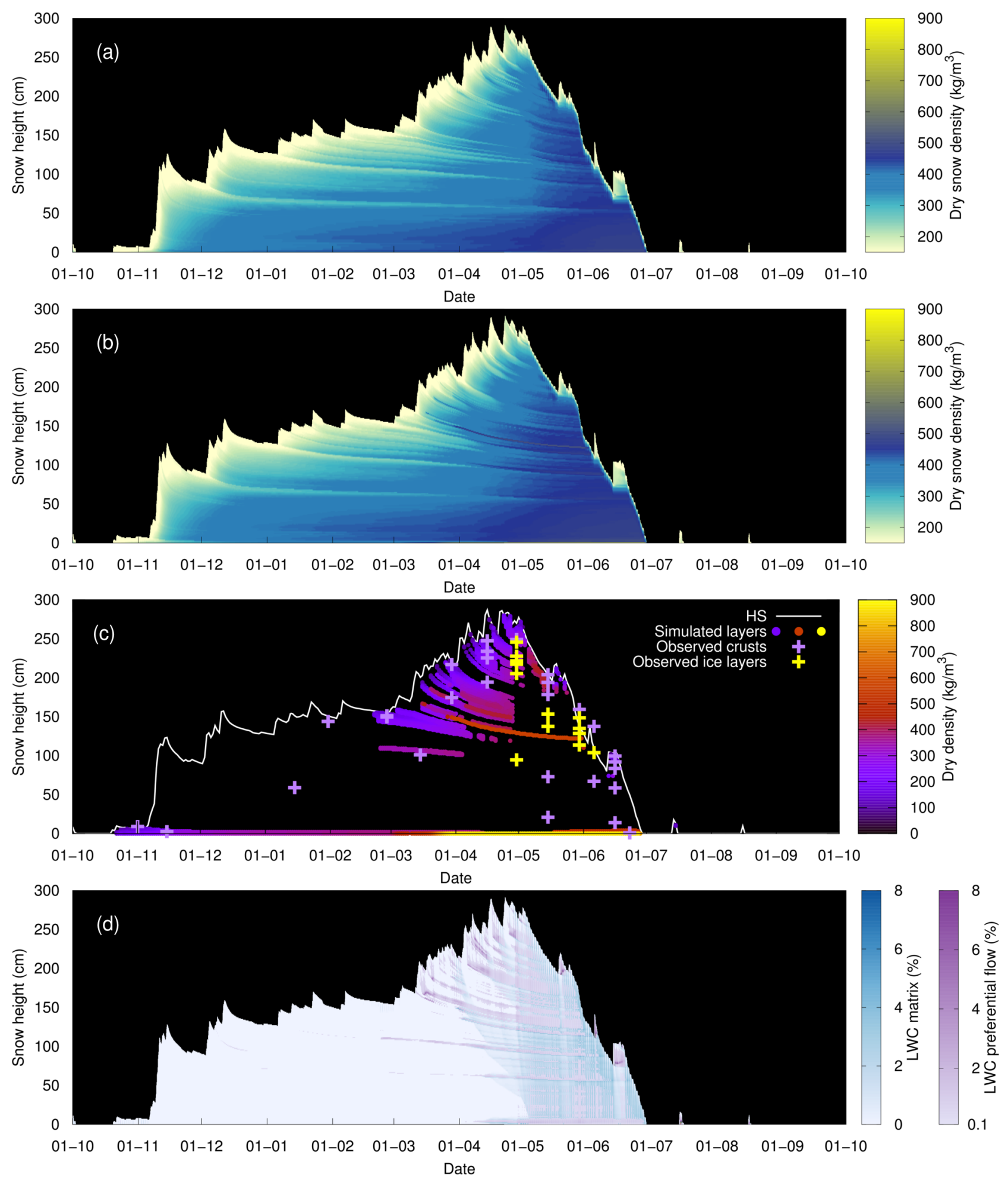

Figure S9: Dry snow density without considering preferential flow (a) and with preferential flow using high resolution simulations (b), validation with field observations (c) and liquid water content in the matrix and preferential flow domain for the simulation with preferential flow (d), for snow season 2008. In (c), modelled layers are shown when they are either a melt-freeze crust, or have a dry snow density exceeding $500 \mathrm{~kg} \mathrm{~m}^{-3}$. For visibility, values of LWC in preferential flow below $0.1 \%$ are ignored in (d). 

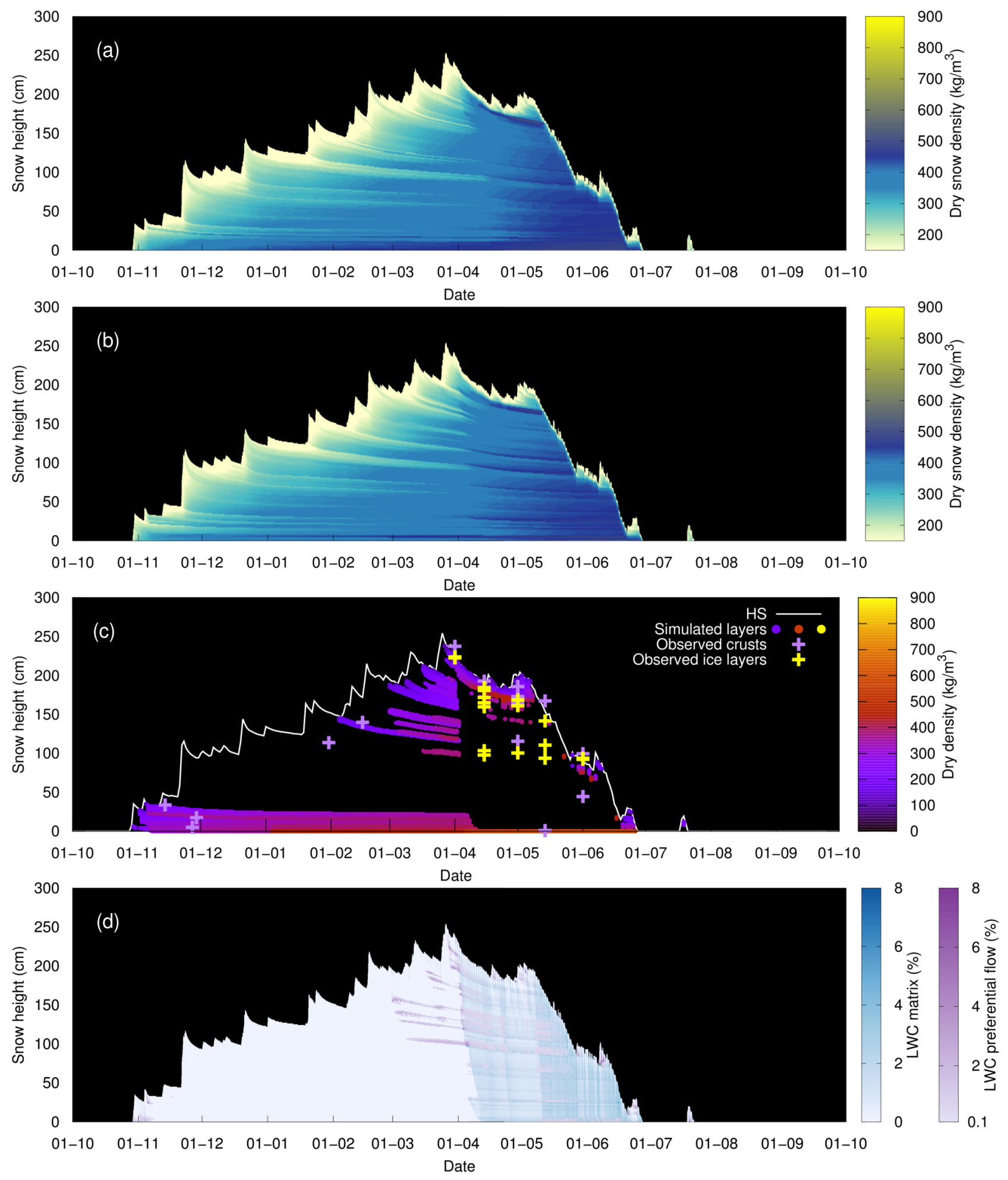

Figure S10: Dry snow density without considering preferential flow (a) and with preferential flow using high resolution simulations (b), validation with field observations (c) and liquid water content in the matrix and preferential flow domain for the simulation with preferential flow (d), for snow season 2009. In (c), modelled layers are shown when they are either a melt-freeze crust, or have a dry snow density exceeding $500 \mathrm{~kg} \mathrm{~m}^{-3}$. For visibility, values of LWC in preferential flow below $0.1 \%$ are ignored in $(\mathrm{d})$. 

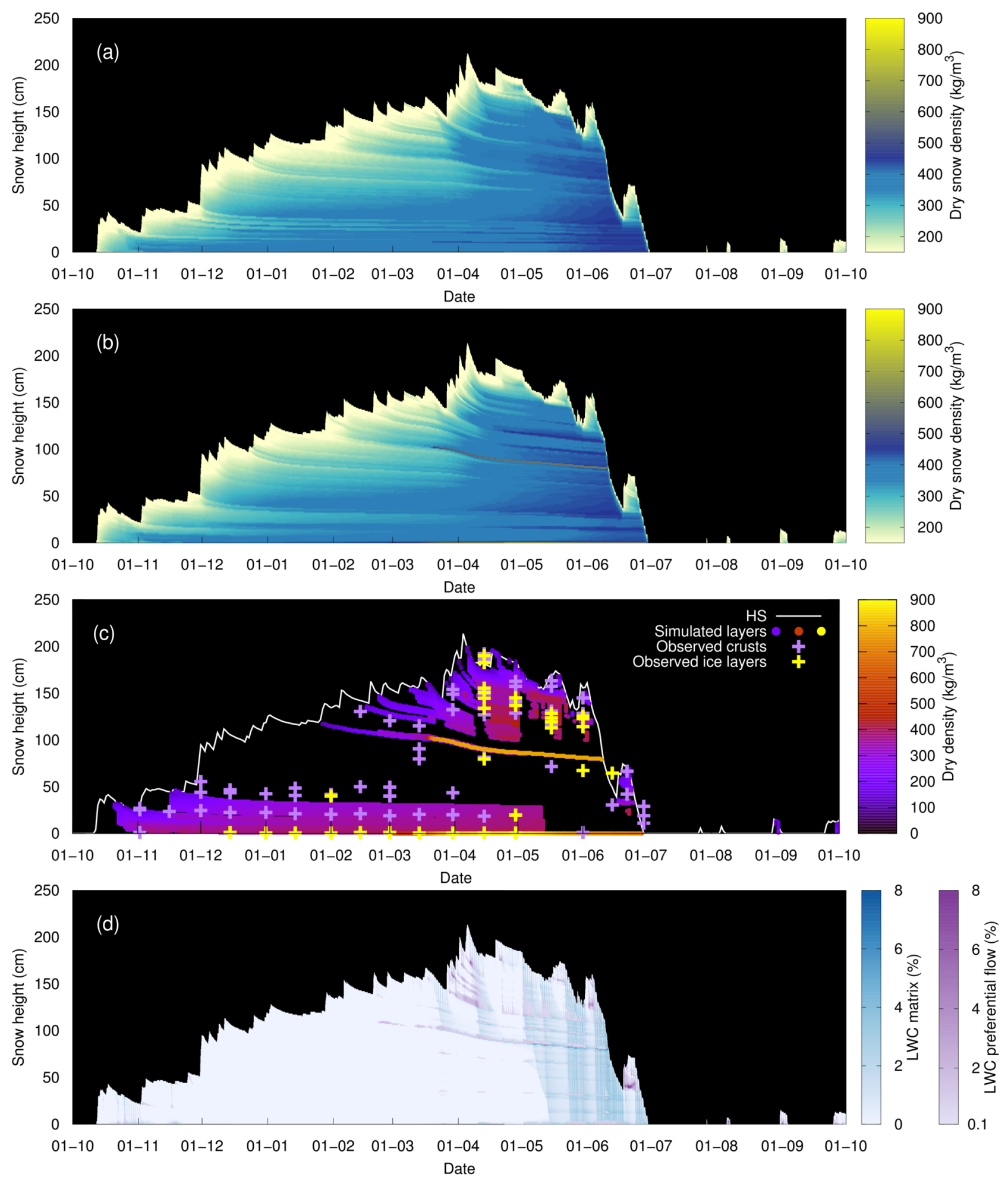

Figure S11: Dry snow density without considering preferential flow (a) and with preferential flow using high resolution simulations (b), validation with field observations (c) and liquid water content in the matrix and preferential flow domain for the simulation with preferential flow (d), for snow season 2010. In (c), modelled layers are shown when they are either a melt-freeze crust, or have a dry snow density exceeding $500 \mathrm{~kg} \mathrm{~m}^{-3}$. For visibility, values of LWC in preferential flow below $0.1 \%$ are ignored in $(\mathrm{d})$. 

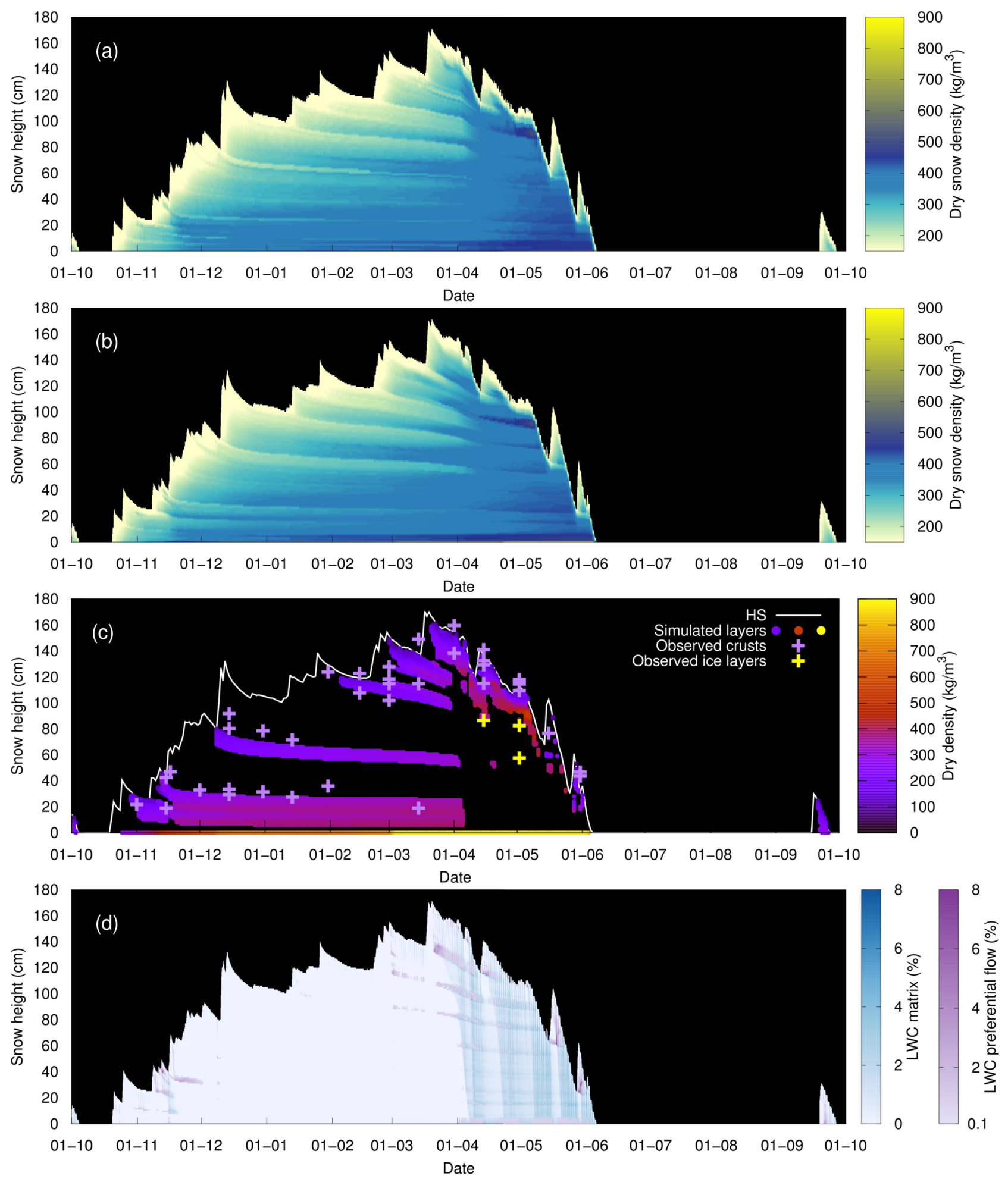

Figure S12: Dry snow density without considering preferential flow (a) and with preferential flow using high resolution simulations (b), validation with field observations (c) and liquid water content in the matrix and preferential flow domain for the simulation with preferential flow (d), for snow season 2011. In (c), modelled layers are shown when they are either a melt-freeze crust, or have a dry snow density exceeding $500 \mathrm{~kg} \mathrm{~m}^{-3}$. For visibility, values of LWC in preferential flow below $0.1 \%$ are ignored in $(\mathrm{d})$. 

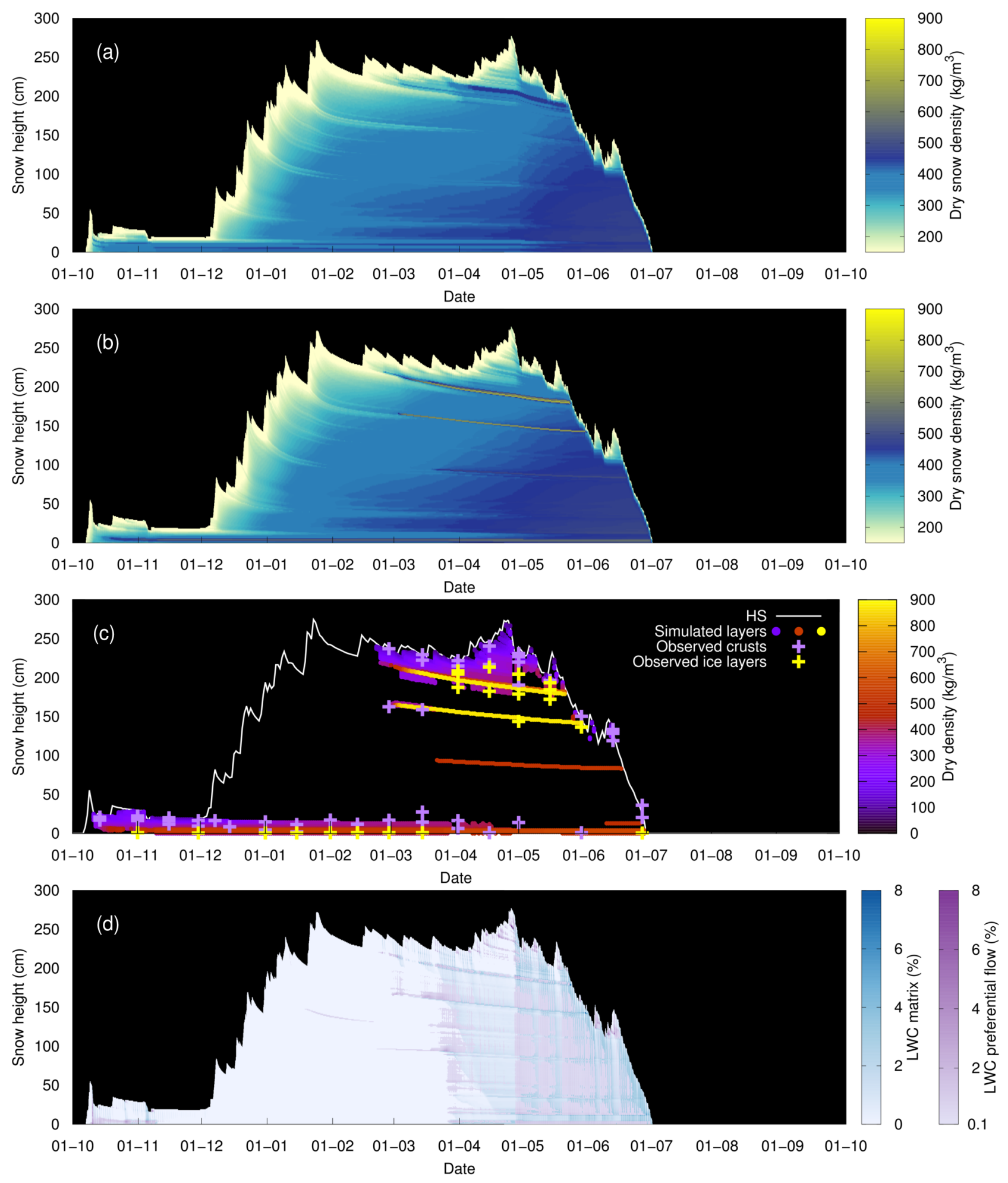

Figure S13: Dry snow density without considering preferential flow (a) and with preferential flow using high resolution simulations (b), validation with field observations (c) and liquid water content in the matrix and preferential flow domain for the simulation with preferential flow (d), for snow season 2012. In (c), modelled layers are shown when they are either a melt-freeze crust, or have a dry snow density exceeding $500 \mathrm{~kg} \mathrm{~m}^{-3}$. For visibility, values of LWC in preferential flow below $0.1 \%$ are ignored in $(\mathrm{d})$. 

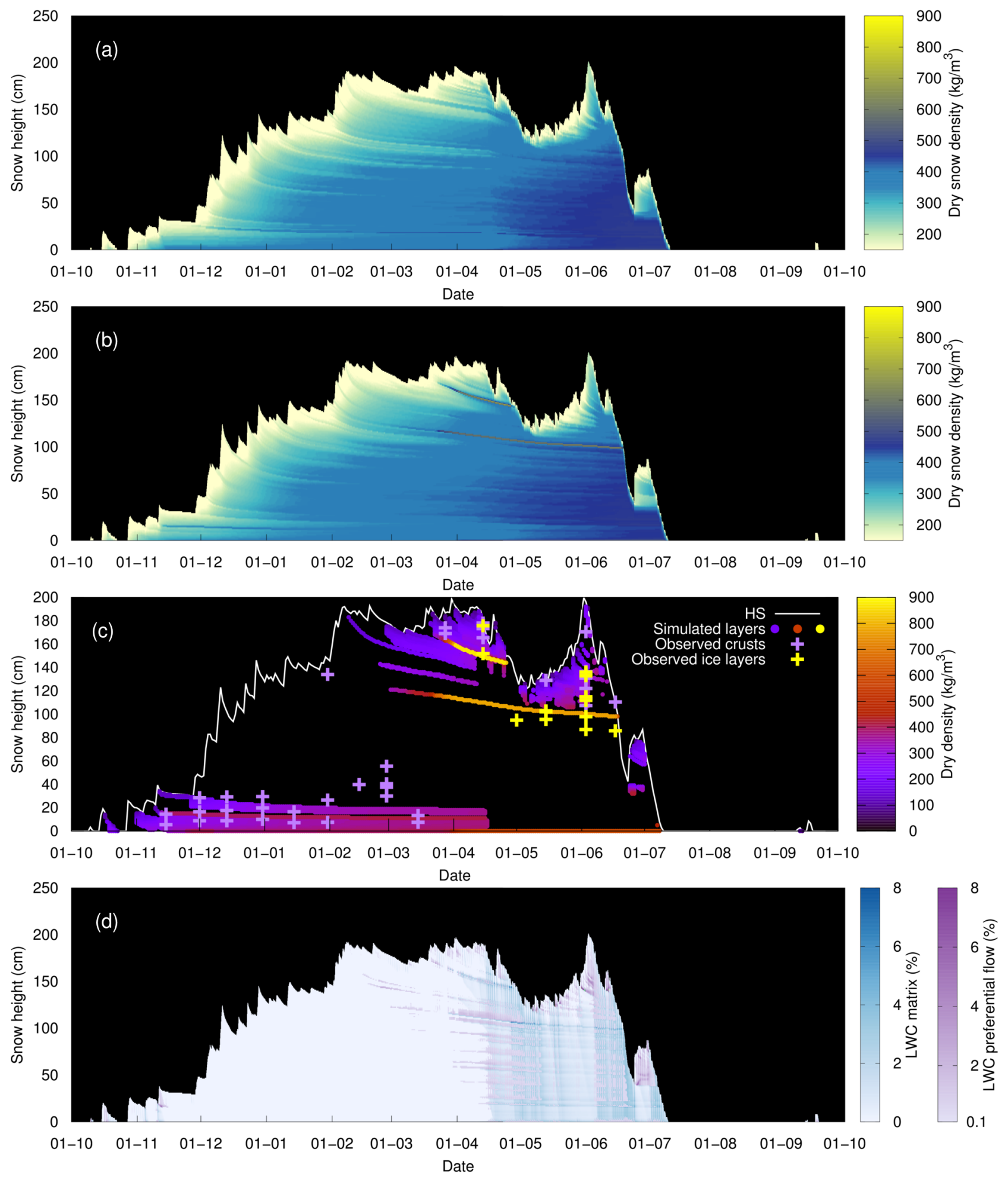

Figure S14: Dry snow density without considering preferential flow (a) and with preferential flow using high resolution simulations (b), validation with field observations (c) and liquid water content in the matrix and preferential flow domain for the simulation with preferential flow (d), for snow season 2013. In (c), modelled layers are shown when they are either a melt-freeze crust, or have a dry snow density exceeding $500 \mathrm{~kg} \mathrm{~m}^{-3}$. For visibility, values of LWC in preferential flow below $0.1 \%$ are ignored in $(\mathrm{d})$. 

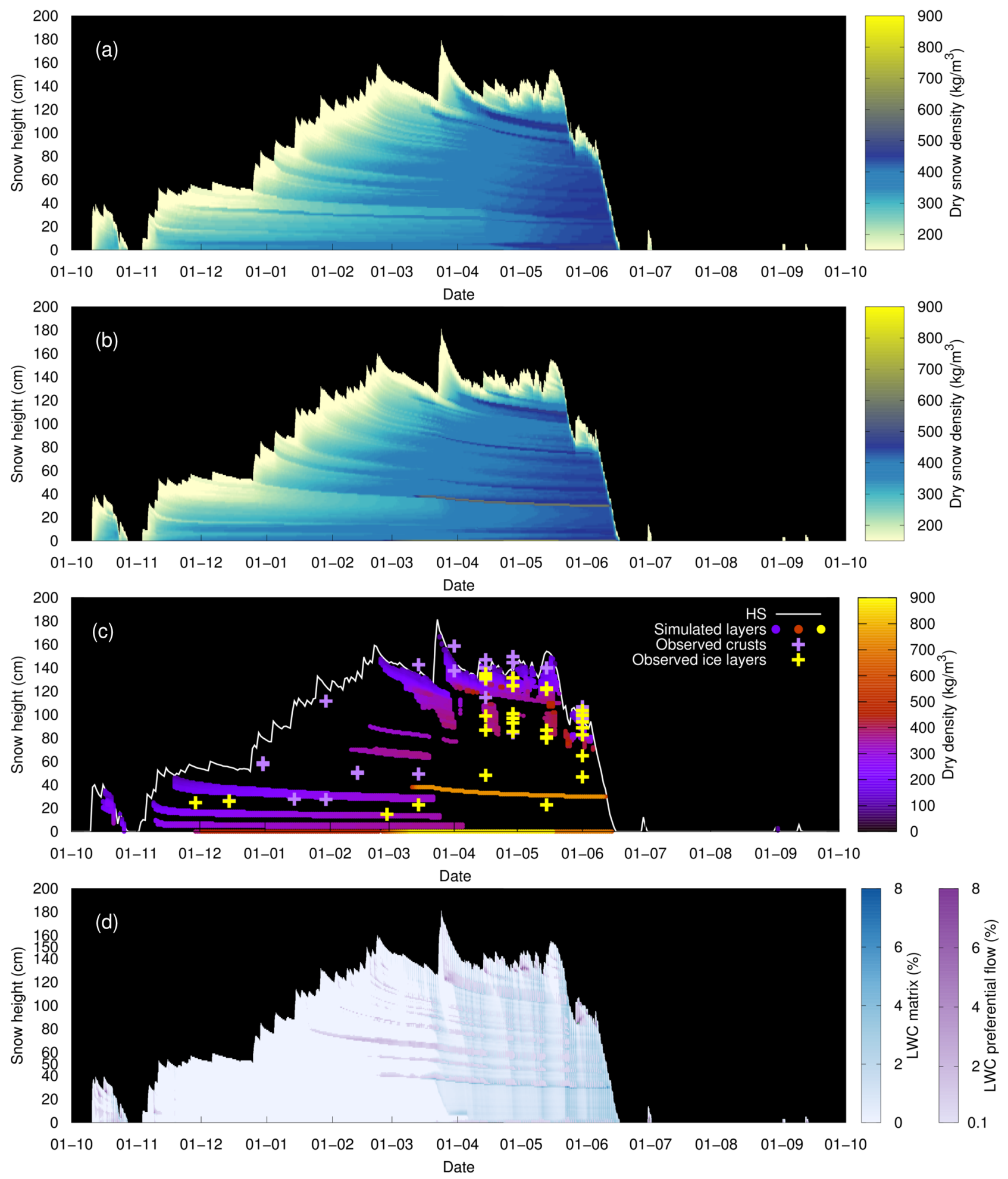

Figure S15: Dry snow density without considering preferential flow (a) and with preferential flow using high resolution simulations (b), validation with field observations (c) and liquid water content in the matrix and preferential flow domain for the simulation with preferential flow (d), for snow season 2014. In (c), modelled layers are shown when they are either a melt-freeze crust, or have a dry snow density exceeding $500 \mathrm{~kg} \mathrm{~m}^{-3}$. For visibility, values of LWC in preferential flow below $0.1 \%$ are ignored in $(\mathrm{d})$. 

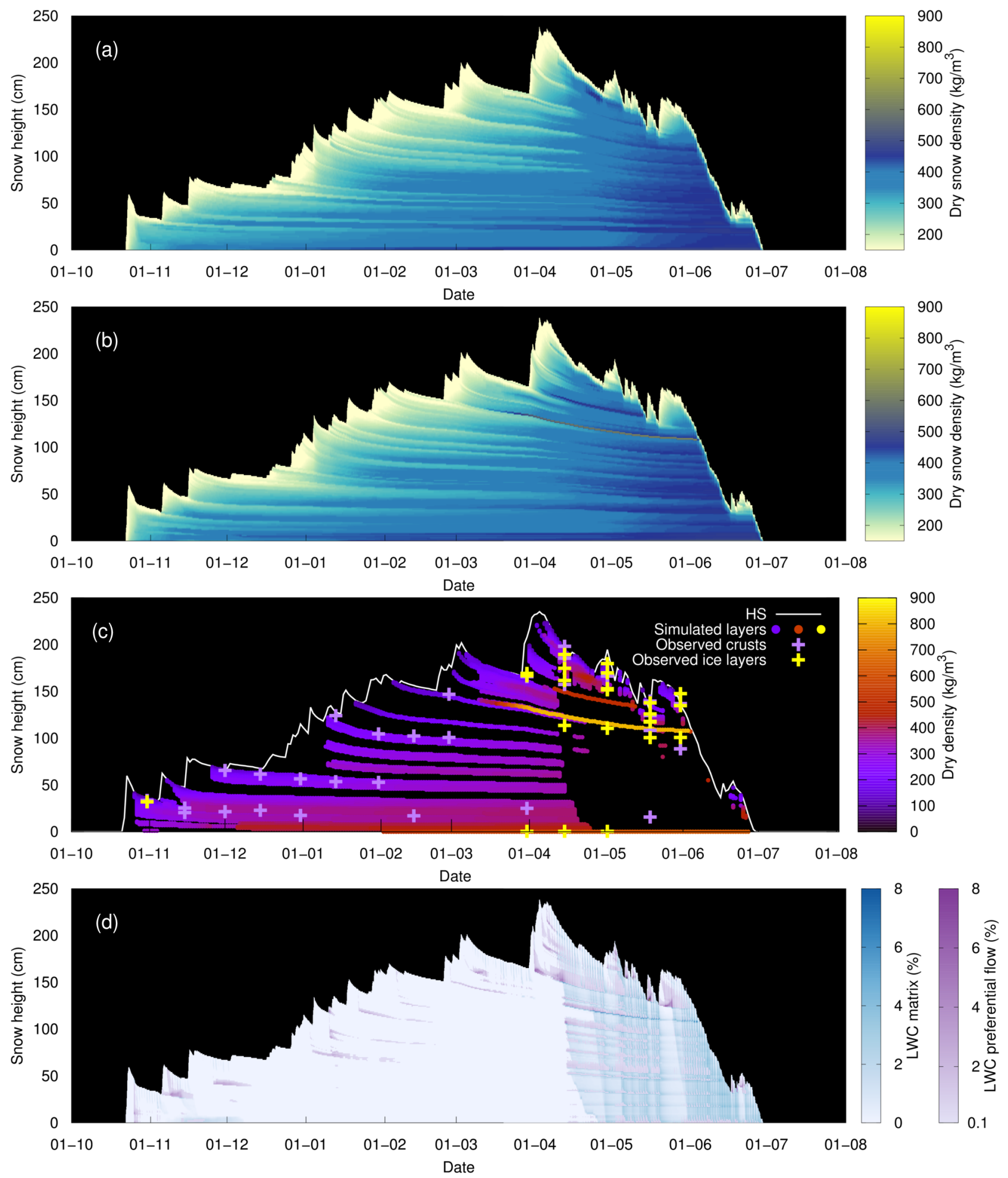

Figure S16: Dry snow density without considering preferential flow (a) and with preferential flow using high resolution simulations (b), validation with field observations (c) and liquid water content in the matrix and preferential flow domain for the simulation with preferential flow (d), for snow season 2015. In (c), modelled layers are shown when they are either a melt-freeze crust, or have a dry snow density exceeding $500 \mathrm{~kg} \mathrm{~m}^{-3}$. For visibility, values of LWC in preferential flow below $0.1 \%$ are ignored in (d). 